Article

\title{
Characterization of Recycled/Virgin Polyethylene Terephthalate Composite Reinforced with Glass Fiber for Automotive Applications
}

\author{
Valentina Volpe ${ }^{1, *(\mathbb{D})}$, Maria Sofia Lanzillo ${ }^{2}$, Alfonso Molaro ${ }^{2}$, Giovanni Affinita ${ }^{2}$ and Roberto Pantani ${ }^{1}$ (D) \\ 1 Department of Industrial Engineering, University of Salerno, Via Giovanni Paolo II 132, Fisciano, \\ 84084 Salerno, Italy; rpantani@unisa.it \\ 2 SAPA s.r.l. Via Appia Est 1, Arpaia, 82011 Benevento, Italy; sofia.lanzillo@sapagroup.it (M.S.L.); \\ alfonso.molaro@sapagroup.it (A.M.); giovanni.affinita@sapagroup.it (G.A.) \\ * Correspondence: vavolpe@unisa.it
}

check for updates

Citation: Volpe, V.; Lanzillo, M.S.;

Molaro, A.; Affinita, G.; Pantani, R. Characterization of Recycled/Virgin Polyethylene Terephthalate Composite Reinforced with Glass Fiber for Automotive Applications. J. Compos. Sci. 2022, 6, 59. https:// doi.org/10.3390/jcs6020059

Academic Editors:

Francesco Tornabene and

Thanasis Triantafillou

Received: 5 January 2022

Accepted: 14 February 2022

Published: 17 February 2022

Publisher's Note: MDPI stays neutral with regard to jurisdictional claims in published maps and institutional affiliations.

Copyright: (c) 2022 by the authors. Licensee MDPI, Basel, Switzerland. This article is an open access article distributed under the terms and conditions of the Creative Commons Attribution (CC BY) license (https:// creativecommons.org/licenses/by/ $4.0 /)$.

\begin{abstract}
The use of recycled polyethylene terephthalate (PET) as a matrix for composite materials based on glass fiber reinforced virgin PET could be a cost-effective and environmentally friendly way to upgrade the bottle-grade recycled PET into engineering-grade PET for injection molding. In this work, a commercial virgin PET reinforced with $50 \%$ wt of glass fibers was compounded by mechanical mixing with a recycled PET, in order to minimize breakage of the glass fibers. The obtained compound, composed by $60 \% \mathrm{wt}$ of recycled pet and $40 \% \mathrm{wt}$ glass fiber reinforced virgin PET, was injection molded at three different mold temperatures $\left(4,40\right.$ and $\left.80^{\circ} \mathrm{C}\right)$ to analyze the effect of crystallization of the material during the production process. The results in terms of thermal and mechanical properties were compared with those obtained from recycled PET molded in the same conditions. The flexural tests and the analysis of thermal resistance showed that by adding $40 \% \mathrm{wt}$ of glass fiber reinforced virgin PET to the recycled PET causes a noticeable improvement of crystallization kinetics and of mechanical properties with respect to that of the pure recycled PET, making it suitable for technical applications.
\end{abstract}

Keywords: glass fiber; injection molding; recycled pet

\section{Introduction}

Polyethylene terephthalate (PET) is one of the most common thermoplastic polyesters. It is a semi-crystalline polymer with excellent mechanical properties and chemical resistance, usually adopted for water bottles, food packaging, synthetic fibers, etc. [1,2]. The excellent properties and its wide fields of use make PET one of the most common polymeric materials in general. However, the large consumption of PET contributes to a significant increase in the amount of waste produced. The great stability of the PET and its resistance to hydrolytic or enzymatic degradation make it a major component of the plastic waste found in the environment [3]. Recycling is a cost-effective method to recover and transform PET into new materials, thus preventing environmental pollution $[4,5]$. The Directive (EU) 2018/852 of the European Parliament represented an important step in that direction, establishing minimum weight targets for plastic recycling from packaging waste of $50 \%$ by the end of 2025 and $55 \%$ by the end of 2030 [6]. Therefore, it becomes necessary to find new applications for recycled plastics and at the same time improve their performance.

The most adopted methods for PET recycling are chemical recycling by hydrolysis and mechanical blending [7]. Chemical recycling involves the production of terephthalic acid (TPA) and ethylene glycol (EG), constituent monomers of the PET, for new polymerization processes by hydrolysis reactions. This type of recycling method enables recovery of the petrochemical constituents of PET wastes to reutilize them for making other synthetic chemicals [8]. The main advantage of chemical recycling is that it makes plastics infinitely 
recyclable without any loss of performance. However, the disadvantages of this method are the high pressure and temperatures and the long times involved, as well the high costs necessary for the subsequent purification of the produced monomers [9]. Mechanical recycling process provides selection, washing and grinding of bottles that are then converted into flakes. After a quick drying process, the flakes are subjected to melt reprocessing by extrusion or injection molding [10,11]. Cost-effectiveness and environmental friendliness make mechanical recycling the most common PET recovery method. However, recycling and reprocessing cause a decrease in melt viscosity and average molecular weight, which can negatively affect the final product's mechanical properties in terms of tensile and impact strength [7]. Some authors have studied the macromolecular changes that occur in PET during its mechanical recycling by extrusion. They assessed that the polymer thermal oxidation is the main source of problems because it can lead to modification of side groups and modification of the macromolecular structure (chain scission, chain extensions, and cross-linking) [12]. These structural modifications limit the applications of the recycled PET. In order to meet specified quality standards of the end-products, it is necessary to make the properties of the recycled PET comparable with those of virgin PET. A possible way is to operate the mechanical recycling with a percentage of virgin PET. Lee et al. studied the properties of blends of recycled PET and various percentages of a fiber-grade virgin PET, obtaining mechanical properties (in particular tensile strength) of the blend 30/70\% recycled/virgin blended fibers comparable to that of the virgin PET fibers [13]. Another way to improve recycled PET properties is to incorporate suitable particles, such as glass or basalt fibers, by melt compounding. Glass fibers are usually adopted as reinforcement due to their remarkable mechanical and physical properties and a rather low price. Adding glass fibers is a cost-effective way to upgrade the recycled polymeric waste by obtaining new materials with a more consistent set of properties to be adopted in a wide range of applications without affecting their environmental performance. Furthermore, glass fibers induce an increase in melt viscosity, a disadvantage that in recycled polymers can become an advantage, given that the mechanical recycling process notoriously involves a decrease in this property [14]. In recent years, several authors investigated the possibility to adopt recycled PET as a matrix for fiber-reinforced composites [15-17]. In 2011 Mondadori et al. [18] developed composites of recycled PET and different percentages of short glass fibers, demonstrating increases in mechanical performances with increasing glass fiber content. The good performances of the recycled PET/glass fiber compound and the impossibility to reuse the recycled PET products coming from multicolored PET bottles in the food industry makes this material available for other technical applications, such as in the automotive industry $[19,20]$. In addition, the increase in mechanical properties and thermo-mechanical resistance due to the glass fiber, upgrades the bottle-grade recycled PET into engineering-grade PET for injection molding and potential substitute for polymers commonly used in the automotive industry $[17,21]$. A few years ago, the confirmation came from Mitsubishi Motors and Toyota Motors Corporation, which developed and produced engine covers in glass-fiber-reinforced recycled PET by injection molding, thus replacing the polyamide normally used for engine covers [22]. In this work, a high percentage of recycled PET coming from multicolored PET bottles was added to a virgin PET reinforced with $50 \%$ of glass fibers, with the aim of reusing the PET waste and at the same time improve its properties to make it suitable for technical applications in the automotive industry, such as cargo trunk floor or aerodynamic shields. The use of PET would greatly facilitate the production of the cargo trunk floor, as they could take place in the same injection molding machine with the fabric covering, without the use of glues, obtaining the same aesthetic result as the currently produced loading cargo parts of. Furthermore, the recycled/virgin PET compound could be a good substitute for the PP with $20 \%$ of glass fiber currently adopted for aerodynamic shields, bringing a significant increase in both the thermal and mechanical resistance of these parts. In particular, the effect of the mold temperature during injection molding process on thermal and mechanical properties was analyzed for both materials. 


\section{Materials and Methods}

In this study, three materials were characterized: a recycled PET (R-PET) derived from post-consumer bottles supplied by Bfor-PET S.r.l. (Benevento, Italy), a virgin PET (V-PET) Arnite AV2 390 reinforced with 50\%wt glass fibers and a compound with $60 \%$ wt R-PET and 40\%wt V-PET (R60-V40). The R60-V40 compound was obtained by mechanical mixing at $60 \mathrm{rpm}$ for $1 \mathrm{~h}$ at ambient temperature before the injection molding process. This mixing method was chosen to minimize polymer degradation and breakage of the glass fibers. R-PET and R60-V40 were processed by injection molding adopting a multicavity mold to produce a set of dissimilar parts used for standard ASTM mechanical tests. For the injection molding process, temperature distribution along the plastification cylinder from 260 to $270{ }^{\circ} \mathrm{C}$, a nozzle temperature of $270{ }^{\circ} \mathrm{C}$ and a hot runner temperature of $280{ }^{\circ} \mathrm{C}$ were set. The samples were produced by imposing three different mold temperatures $(4,40$, and $80^{\circ} \mathrm{C}$ ) to analyze the effect of the crystallization of the material during the production process on its mechanical properties. The cooling times of the samples inside the mold are $40 \mathrm{~s}$ for mold temperatures of $40^{\circ} \mathrm{C}$ and $80^{\circ} \mathrm{C}$, and $30 \mathrm{~s}$ for mold temperature of $4{ }^{\circ} \mathrm{C}$. The characteristics of the analyzed materials are shown in Table 1.

Table 1. Characteristics of the analyzed materials.

\begin{tabular}{cccc}
\hline Material & Recycled Percentage & Virgin Percentage & $\begin{array}{c}\text { Glass Fiber Content } \\
\text { Percentage }\end{array}$ \\
\hline R-PET & 100 & 0 & 0 \\
V-PET & 0 & 100 & 50 \\
R60-V40 & 60 & 40 & 20 \\
\hline
\end{tabular}

The average molecular weight of R-PET and V-PET was evaluated by measuring the intrinsic viscosity in trifluoroacetic acid (TFA) at $30^{\circ} \mathrm{C}$, following the method described in ASTM D 4603. The intrinsic viscosity is related to the molecular weight by means of the Mark-Houwink equation:

$$
[\eta]=K M^{\alpha}
$$

The adopted parameters $K$ and $\alpha$ are $4.33 \times 10^{-4}$ and 0.68 , respectively [23]. The resulting average molecular weights are 25,000 g/mol for R-PET and 44,000 g/mol for V-PET.

\subsection{Calorimetric Analysis}

Calorimetric analysis was performed using a DSC 822 differential scanning calorimeter (Mettler-Toledo, Columbus, OH, USA) in a nitrogen atmosphere. A small amount of material was placed into an aluminium pan and heated at $10{ }^{\circ} \mathrm{C} / \mathrm{min}$ from $25^{\circ} \mathrm{C}$ to $200{ }^{\circ} \mathrm{C}$; kept for $1 \mathrm{~min}$ at $200{ }^{\circ} \mathrm{C}$ and then cooled down at $10^{\circ} \mathrm{C} / \mathrm{min}$ to $25^{\circ} \mathrm{C}$. The crystalline degree was evaluated by the following equation:

$$
\chi_{c}=\frac{\Delta H_{m}-\Delta H_{c}}{\Delta H_{m}^{0}} \cdot 100
$$

where $\Delta H_{m}$ is the enthalpy of melting, $\Delta H_{c}$ the enthalpy of crystallization (both normalized with respect to the polymer mass inside the sample, namely neglecting the mass of glass fibers) and $\Delta H_{m}^{0}$ the enthalpy of melting of a hypothetical $100 \%$ crystalline PET, assumed equal to $140.1 \mathrm{~J} / \mathrm{g}[24,25]$. The test and the analysis of the results were conducted according to ASTM D3418-08.

\subsection{Rheological Analysis}

Rheological measurements were conducted by a shear strain-controlled rheometer (ARES-TA instruments, New Castle, DE, USA) with a parallel-plate geometry and an imposed gap of $1 \mathrm{~mm}$. The frequency sweep tests were performed at 240,260 and $280{ }^{\circ} \mathrm{C}$ 
with a strain value of $10 \%$, value included in the linear viscoelastic range. The investigated frequency range was $0.1-150 \mathrm{rad} / \mathrm{s}$. The rheological tests were conducted by melting the injection molded samples. In order to assess the effect of the degradation induced by processing, rheological tests were also conducted on the material before the injection molding process. As mentioned above, the R60-V40 compound was obtained by mechanical mixing before the injection molding process. This means that the pellets of the compound were not available. In order to obtain a blend with the minimum possible amount of mechanical stress, $5 \mathrm{~g}$ of pellets in the weight ratio to reproduce the R60-V40 were melt mixed in a Minimax CS-183 MMX (CSI Co., Easton, PA, USA) at a temperature of $240{ }^{\circ} \mathrm{C}$ maintained for $3 \mathrm{~min}$ with a rotor speed set at $30 \mathrm{rpm}$. This material will be referred to as R60-V40 "pellets" in the following.

\subsection{Mechanical Characterization}

The flexural resistance of the specimen was measured in three-point bending mode by a universal testing machine (ATSFAAR TC1000, Milano, Italy) equipped with a load cell of $1 \mathrm{kN}$. The specimen in form of bar of rectangular cross section was rest on two supports with span of $40 \mathrm{~mm}$ and loaded by means of a loading nose midway between the supports with a rate of nose of $2 \mathrm{~mm} / \mathrm{min}$. The test and the analysis of the results were conducted according to ASTM D 790-03.

\subsection{Thermal Resistance}

The analysis of thermal resistance was carried out by a DMA 8000 system (Perkin Elmer, Waltham, MA, USA). The samples (4.06 mm thick and $12.34 \mathrm{~mm}$ wide) were placed in a three-point flexural test configuration, on two supporting pins distant $35 \mathrm{~mm}$, and loaded at the middle point with a constant force of $8 \mathrm{~N}$. A temperature scan from room temperature to $180{ }^{\circ} \mathrm{C}$ at $5{ }^{\circ} \mathrm{C} / \mathrm{min}$ was imposed and the displacement at the middle point was measured.

\section{Results and Discussion}

\subsection{Preliminary Analysis}

A preliminary thermal analysis was made on the three materials in the form of pellets. Figure 1 shows the melting peaks obtained by DSC analysis of V-PET, R-PET, and R60-V40 in the form of pellets.

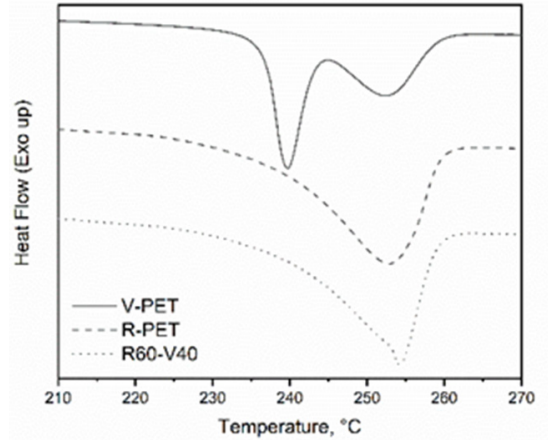

(a)

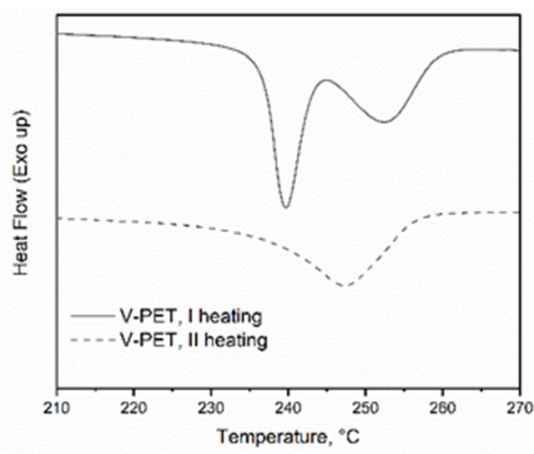

(b)

Figure 1. Melting peaks of V-PET, R-PET and R60-V40 observed during the first heating at DSC (a). Melting peaks of V-PET during first and second heating (b).

From Figure $1 \mathrm{a}$ it is possible to observe that, during the first DSC heating stage, the V-PET exhibits two melting peaks, one at $240{ }^{\circ} \mathrm{C}$ and another one at $252^{\circ} \mathrm{C}$, ascribable to the melting of different crystal structures. The peak at lower temperature can be attributed to the melting of small imperfect crystals formed at constant crystallization temperature, while the more perfect crystals melt at a higher temperature due to a reorganization undergone 
during the DSC scan. In the melting peak of the R60-V40 compound, only a small shoulder can be seen. At the same time, the recycled material (R-PET) shows a single melting peak because of its bi-axial crystalline orientation that does not allow a reorganization of the polymer chains during the temperature scan [26]. Figure $1 \mathrm{~b}$ shows the melting peaks of the V-PET during first and second heating. The comparison reveals that the double peak observed during the first heating at DSC become a single peak in the second heating.

All the materials show an onset melting temperature larger than $240^{\circ} \mathrm{C}$, suggesting that this temperature is the lowest possible for processing. The compound R60-V40 in the form of pellet was thus subject to rheological measurements (Figure 2) with the aim of assessing the processability of the material at temperatures equal or larger than $240{ }^{\circ} \mathrm{C}$.

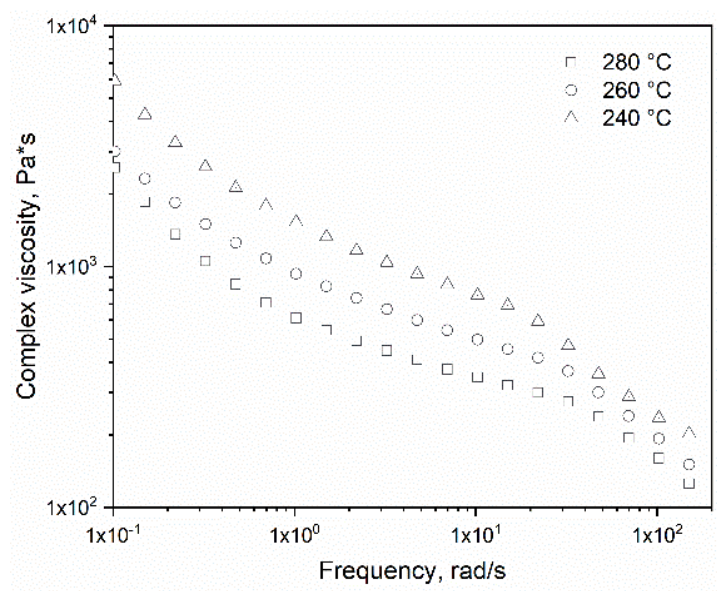

(a)

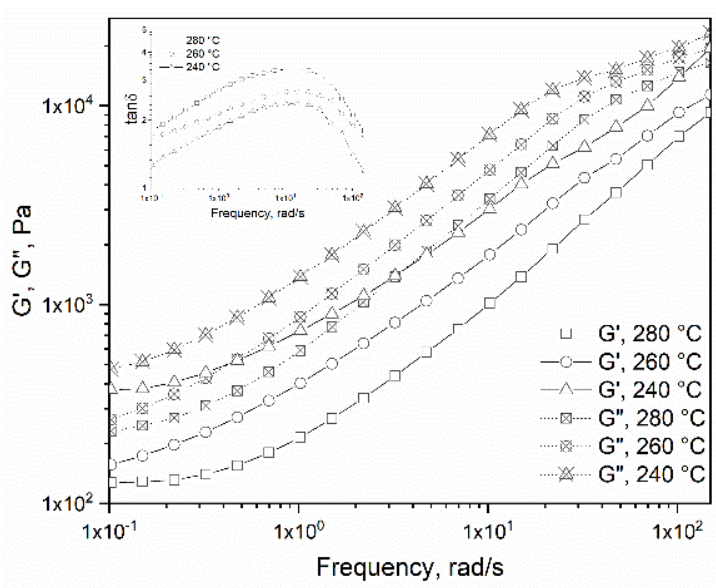

(b)

Figure 2. Dependence of complex viscosity (a) and storage and loss moduli (b) of R60-V40 from the frequency at 240,260 , and $280^{\circ} \mathrm{C}$.

R60-V40 composite shows a shear-thinning behavior. The presence of glass fiber in the polymer melt involves a "yielding" behavior: on increasing the frequency the viscosity decreases, seems to tend to a plateau but then decreases again with a larger slope (on a log-log plot) [27]. By analyzing the dependence of storage $\left(G^{\prime}\right)$ and loss $\left(G^{\prime \prime}\right)$ moduli from frequency it is possible to observe that the loss modulus is higher than the storage modulus in the whole frequency range investigated: the viscous nature of the material dominates the elastic behavior in the investigated range of frequency and temperature. The presence of a secondary plateau at low frequency $(0.1-0.5 \mathrm{rad} / \mathrm{s})$ indicates a finely and well-dispersed viscoelastic solid phase in a molten matrix and suggests that there is good adhesion between glass fibers and PET matrix in the molten state $[28,29]$. The recycled PET and its compound with V-PET (the virgin material reinforced with glass fiber) were processed by injection molding by imposing different mold temperatures. Figure 3 shows the comparison between the rheological behavior of the compound R60-V40 processed and in the form of pellet, in order to estimate the effect of the process on the rheological properties. As it is possible to note, the injection molding process results in a reduction in viscosity and storage and loss moduli while maintaining the characteristic behavior. Most of this reduction can be attributed to the breaking of glass fibers: the injection molding process, as well as causing a slight reduction in the rheological properties of the polymer, determinates a reduction of the fiber's dimensions. In order to measure the glass fiber dimension in the different process stages, the V-PET, the R60-V40 in the form of pellets, and the processed R60-V40 were burnt in a specific oven in an oxidative atmosphere at $450{ }^{\circ} \mathrm{C}$ for $1 \mathrm{~h}$. The oxidative process caused the complete degradation of the polymeric part of the samples, while the glass fibers remained unaltered. The glass fibers were observed by an optical microscope and measured by a software for the analysis of the images, to quantify the effect of the different processes undergone on the length of the glass fibers. From 
Figure 4, in which a comparison of the glass fiber length distribution in V-PET, R60-V40 in the form of pellets and processed R60-V40, it is possible to observe that the fibers undergo a first breakage due to the melt mixing process of V-PET with R-PET. The injection molding process of the compound causes a further breakage of the glass fibers. For this reason, the distribution curve moves further towards low glass fiber lengths. This reduction of length could reduce the properties of the compound with respect to the virgin material.

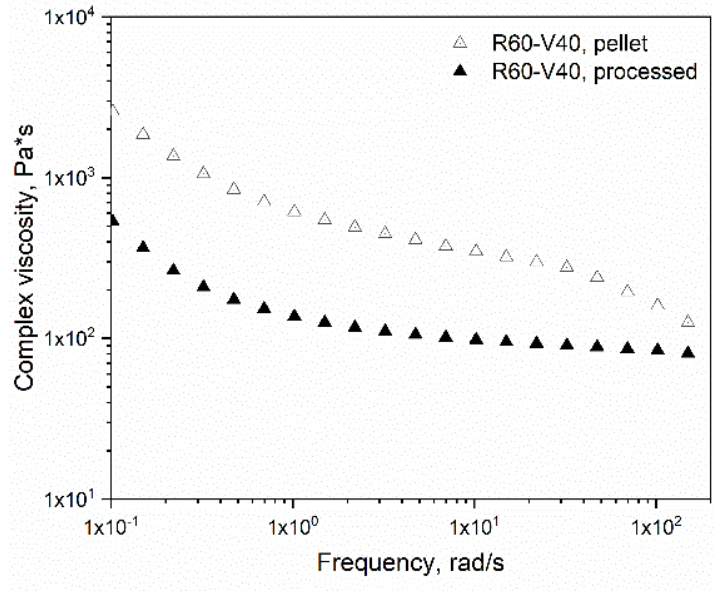

(a)

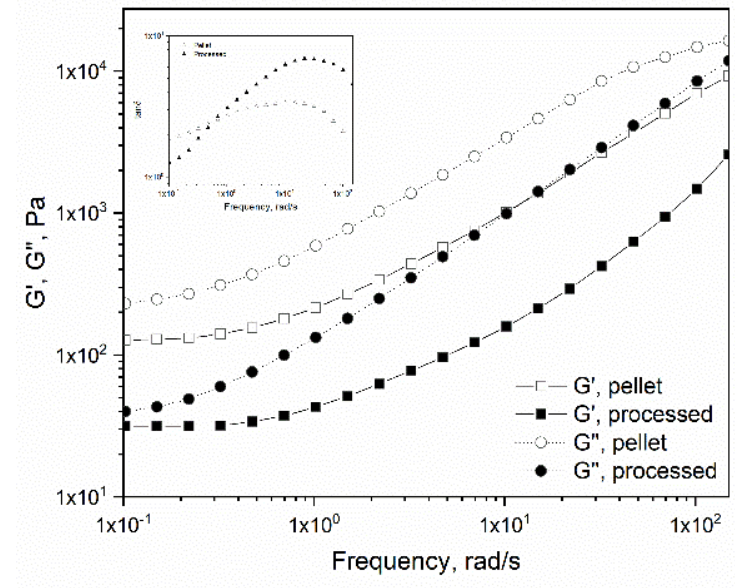

(b)

Figure 3. Dependence of complex viscosity (a) and storage and loss moduli (b) of R60-V40 in the form of pellet and processed from frequency at $280^{\circ} \mathrm{C}$.

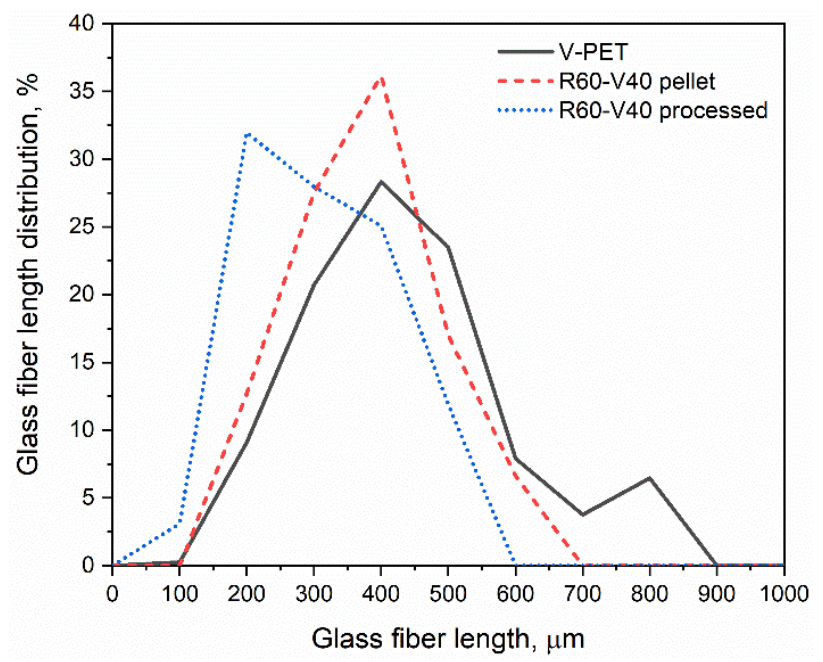

Figure 4. Glass fiber length distribution in V-PET, R60-V40 pellet, and R60-V40 processed.

\subsection{Analysis of Crystallinity in the Molded Samples}

Samples of R-PET and R60-V40 were produced by the injection molding process in order to compare the properties of the recycled PET with those of the same material compounded with the virgin PET reinforced with glass fiber. In particular, different mold temperatures were applied in order to analyze the effect of this parameter on the properties of the samples. The produced samples were subject to calorimetric analysis and flexural tests, in order to study the dependence of their properties on the mold temperature. Figure 5 shows the thermograms of the heating of R-PET and R60-V40 samples from 25 to $270{ }^{\circ} \mathrm{C}$. The corresponding values of crystallization and melt temperatures $\left(\mathrm{T}_{\mathrm{C}}\right.$ and $\left.\mathrm{T}_{\mathrm{m}}\right)$ and crystalline degree $\left(X_{c}\right)$ are reported in Table 2. 


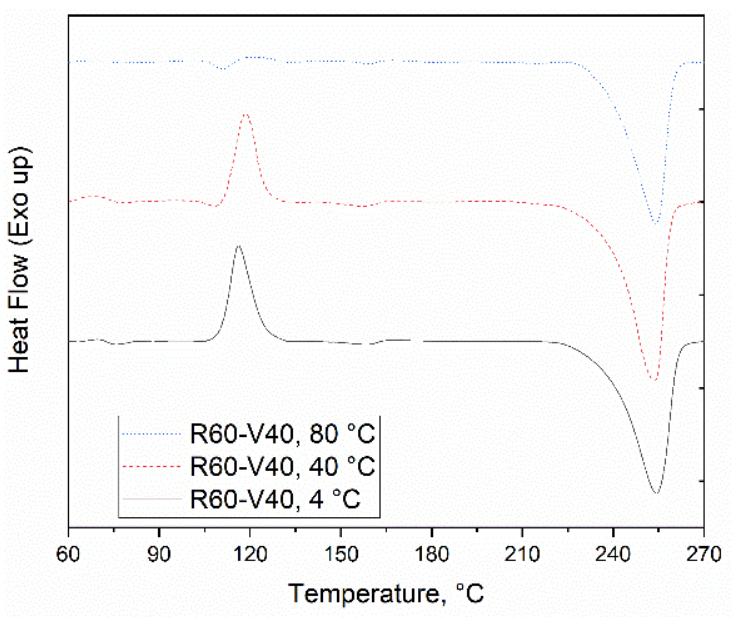

(a)

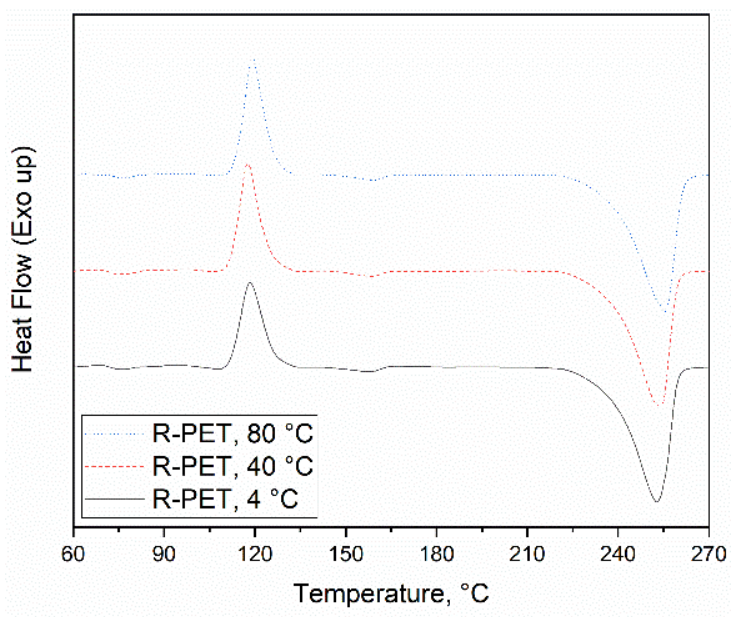

(b)

Figure 5. Thermograms of R60-V40 (a) and R-PET (b) molded with different mold temperatures.

Table 2. Results of DSC analysis on R-PET and R60-V40.

\begin{tabular}{ccccccc}
\hline \multirow{2}{*}{$\begin{array}{c}\text { Mold } \\
\text { Temperature, }\end{array}{ }^{\circ} \mathbf{C}$} & \multicolumn{3}{c}{ R-PET } & \multicolumn{3}{c}{ R60-V40 } \\
\cline { 2 - 7 } & $\mathbf{T c}{ }^{\circ} \mathbf{C}$ & $\mathbf{T m}^{\circ}{ }^{\circ} \mathbf{C}$ & $\mathbf{X c}, \mathbf{\%}$ & Tc, $^{\circ} \mathbf{C}$ & $\mathbf{T m}^{\circ}{ }^{\circ} \mathbf{C}$ & $\mathbf{X c}, \mathbf{\%}$ \\
\hline 4 & 118.4 & 252.8 & 16.5 & 116.2 & 254.1 & 16.8 \\
40 & 117.6 & 253.3 & 16.4 & 118.5 & 253.9 & 19.6 \\
80 & 119.3 & 255.5 & 15.9 & - & 253.9 & 25.6 \\
\hline
\end{tabular}

The effect of the mold temperature is more visible in the thermograms of R60-V40 compounds, in which the crystallinity peak is smaller and smaller as the mold temperature increases. For the R-PET samples the variation of the crystallinity peak with the mold temperature is almost imperceptible. In Figure 6 the variation of the crystalline degree evaluated by Equation (1) with the mold temperature can be observed. The results are average values of three measurements.

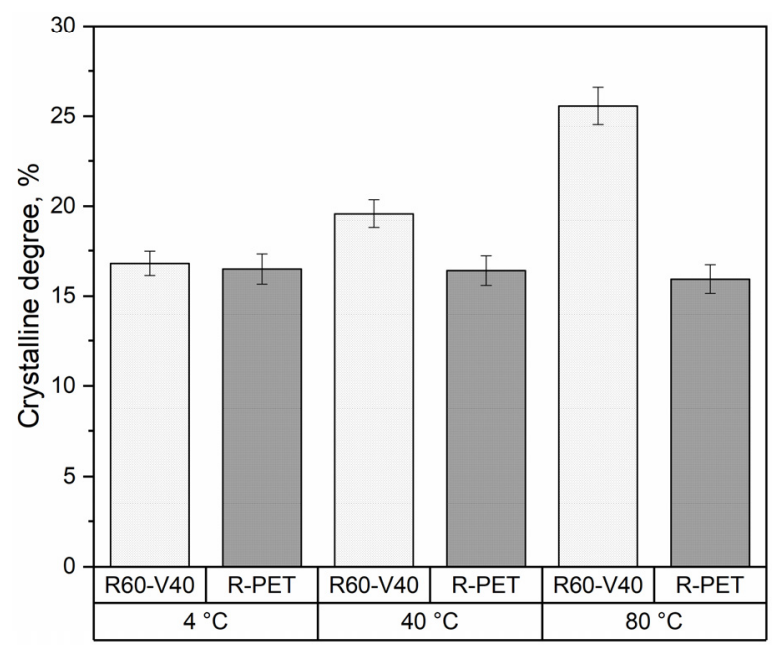

Figure 6. Crystalline degree of R-PET and R60-V40 molded at different mold temperatures.

The histogram confirms the evaluation of the crystallinity peaks: the crystalline degree of the R-PET is almost constant with the mold temperature. In contrast, in the case of R60-V40 compound, an appreciable increase in crystallinity can be observed, until it reaches the maximum possible crystallinity in the case of mold temperature equal to $80^{\circ} \mathrm{C}$. The results suggest that the compound presents a faster crystallization kinetics with 
respect to the R-PET, which is noteworthy, since PET is considered a slowly crystallizing material which normally does not crystallize significantly during injection molding. This phenomenon is mainly due to the nucleating effect of glass fibers, consistently with what reported in the literature [18]. The effect is more and more evident on increasing the mold temperature, and thus on decreasing the cooling rate.

\subsection{Mechanical Testing of the Molded Samples}

On the same samples, the response to a three-point bending test was evaluated. Figure 7 shows typical flexural stress-strain curves of the recycled PET and the compound molded at the three mold temperatures. From the graph, a considerable increase in the flexural modulus of the compound is clear with respect to the modulus of the recycled PET. Therefore, adding $40 \%$ of virgin PET reinforced with glass fibers to the recycled PET allows obtaining acceptable flexural modulus values for a material to be used in the automotive industry.

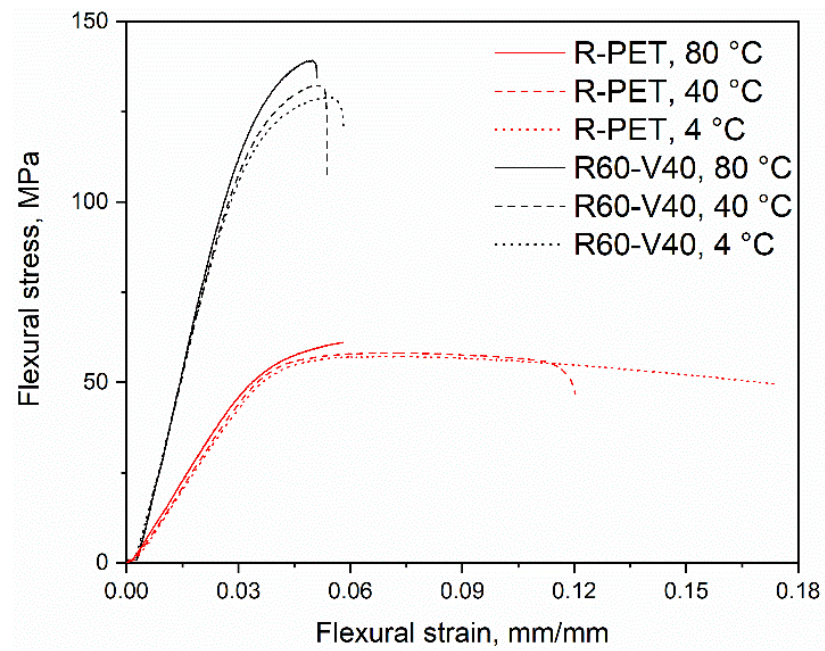

Figure 7. Stress-strain curves of R-PET and R60-V40 molded at different mold temperatures.

Besides comparing the mechanical behavior of the recycled PET with the R60-V40 compound, it is interesting to evaluate the effect of the mold temperature, and therefore of the crystallinity, on the flexural properties of the two materials. Figure 8 shows the flexural modulus of R-PET and R60-V40 molded at different mold temperatures. The results are average values of five measurements. The histograms reveal an increase in the flexural modulus with the mold temperature. However, it is possible to observe from Figure 7 that a low mold temperature determines a higher maximum flexural strain. In particular, in R-PET, the samples molded at $4{ }^{\circ} \mathrm{C}$ showed a very high flexural strain without breaking. The results reported in Table 2 clearly show that, in the case of R-PET, flexural strain at break and percentage of broken samples during the test increase with the mold temperature. The values in Tables 2 and 3 demonstrate that on increasing the crystallinity of the molded part (because of a higher mold temperature), the material assumes a brittler behavior. By reducing the mold temperature at $4{ }^{\circ} \mathrm{C}$, the crystalline degree decreases, and the material takes a more ductile behavior. 


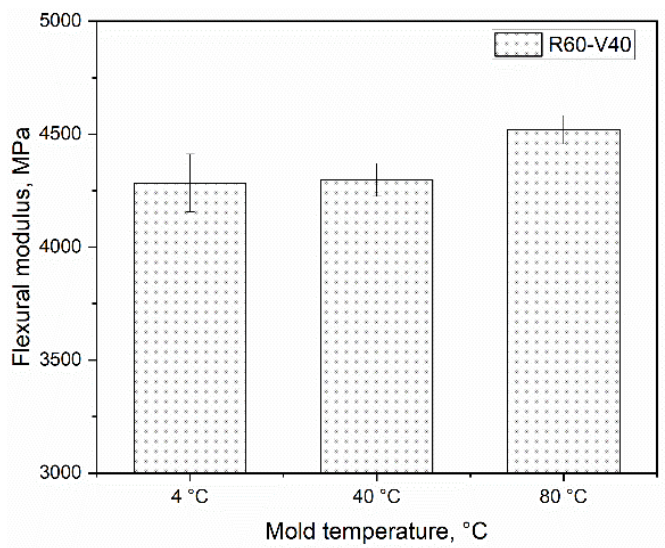

(a)

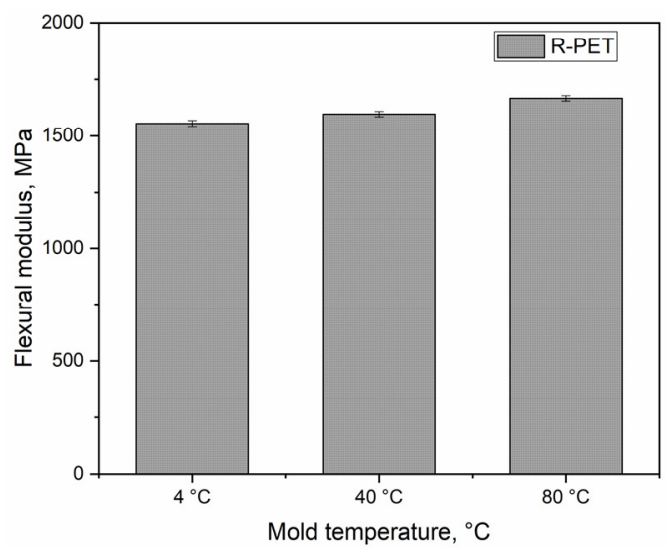

(b)

Figure 8. Flexural modulus of R60-V40 (a) and R-PET (b) molded at different mold temperatures.

Table 3. Results of three-point bending on R-PET and R60-V40.

\begin{tabular}{|c|c|c|c|c|c|c|}
\hline \multirow{2}{*}{$\begin{array}{c}\text { Mold } \\
\text { Temperature, }{ }^{\circ} \mathrm{C}\end{array}$} & \multicolumn{3}{|c|}{ R-PET } & \multicolumn{3}{|c|}{ R60-V40 } \\
\hline & $\begin{array}{c}\text { Flexural } \\
\text { Modulus, MPa }\end{array}$ & $\begin{array}{l}\text { Flexural Strain at } \\
\text { Break, } \mathrm{mm} / \mathrm{mm}\end{array}$ & $\begin{array}{l}\text { Broken Samples } \\
\text { Percentage }\end{array}$ & $\begin{array}{c}\text { Flexural } \\
\text { Modulus, MPa }\end{array}$ & $\begin{array}{l}\text { Flexural Strain at } \\
\text { Break, } \mathrm{mm} / \mathrm{mm}\end{array}$ & $\begin{array}{c}\text { Broken Samples } \\
\text { Percentage }\end{array}$ \\
\hline 4 & 1554.40 & - & $0 \%$ & 4283.38 & 0.058 & $100 \%$ \\
\hline 40 & 1595.52 & 0.030 & $20 \%$ & 4297.80 & 0.056 & $100 \%$ \\
\hline 80 & 1665.73 & 0.061 & $100 \%$ & 4519.81 & 0.051 & $100 \%$ \\
\hline
\end{tabular}

The thermal resistance tests allowed us to evaluate the variation of the strain with increasing temperature starting from room temperature. As it is possible to observe from Figure 9, the strain values of the recycled PET at all the mold temperatures begin to increase at about $65^{\circ} \mathrm{C}$, reaching immediately higher strain percentages, index of the softening of the material, already at very low temperatures. The test stops when the apparatus detects that the sample does not withstand the imposed force. On the contrary, the strain percentage of the R60-V40 compounds begins to increase at slightly higher values and remains at low values (below $2 \%$ ) up to the highest investigated temperatures. Furthermore, increasing mold temperature improves the performance of both materials, so that for the sample molded at $80^{\circ} \mathrm{C}$ the maximum strain remains below $1 \%$ up to $180{ }^{\circ} \mathrm{C}$. This suggests that the material can also be adopted in a high-temperature environment.

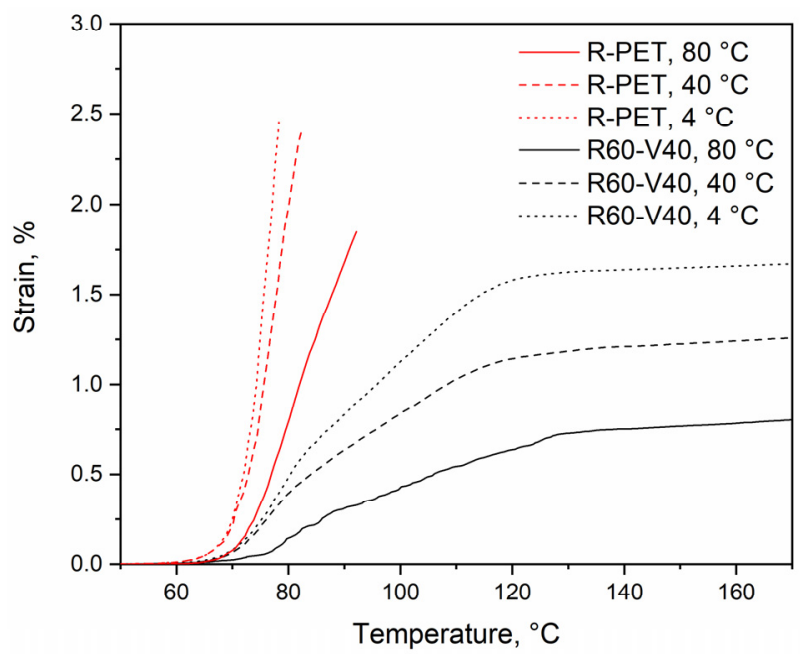

Figure 9. Dependence of the strain from the temperature of R-PET and R60-V40 molded at different molding temperatures. 


\section{Conclusions}

In this work, the characterization of a recycled PET and of a compound with $60 \%$ recycled PET and $40 \%$ of a virgin PET reinforced with glass fibers was made, in order to evaluate the improvements in properties of the compound with respect to the recycled PET. The recycled PET and the compound were processed at three different mold temperatures to analyze the effect of this parameter on the crystallization of the material during the production process and on its mechanical properties. The compounding and the injection molding processes cause a progressive breakage of the glass fibers, and therefore a reduction in the rheological properties. The mechanical tests show that the compounding of the recycled PET with a virgin PET reinforced with glass fibers greatly improves the properties of the final parts with respect to the recycled PET, making it a cost-effective and environmentally friendly substitute of the traditional engineering polymers.

For the recycled PET, the increase in mold temperature does not determine an appreciable variation of crystallinity, while the flexural modulus increases slightly. By adding a percentage of virgin PET reinforced with glass fibers, the effect of the mold temperature on the crystalline degree becomes more evident: low mold temperatures determine low crystallinity and low flexural modulus. However, the maximum flexural strain increases at low mold temperatures and the percentage of broken samples decreases, indicating a more ductile and less brittle material. The faster crystallization kinetics of the compound with respect to the R-PET can be attribute to the nucleating effect of glass fibers. The effect is more and more evident on increasing the mold temperature, and thus on decreasing the cooling rate.

The thermal resistance tests allowed to assess that R60-V40 compounds show good performances up to the highest investigated temperatures, $180^{\circ} \mathrm{C}$, with better properties induced by higher mold temperatures.

The recycled/virgin PET compound could be adopted to substitute the material currently used for cargo trunk floors. The use of PET would greatly facilitate the production of these automotive parts, as they could take place in the same injection molding machine with the fabric covering, without the use of glues, obtaining the same aesthetic result as the loading cargo of current production. Furthermore, the recycled/virgin PET compound could be a good substitute for the PP with $20 \%$ of glass fiber currently adopted for aerodynamic shields, bringing a significant increase in both the thermal and mechanical resistance of these parts.

Author Contributions: Conceptualization, M.S.L., A.M., G.A., V.V. and R.P.; methodology, V.V. and R.P.; visualization, M.S.L., A.M., G.A., V.V. and R.P.; validation, M.S.L., A.M., G.A., V.V. and R.P.; writing—original draft preparation, V.V. and R.P.; writing—review and editing, V.V. and R.P. All authors have read and agreed to the published version of the manuscript.

Funding: This research received no external funding.

Institutional Review Board Statement: Not applicable.

Informed Consent Statement: Not applicable.

Data Availability Statement: The data presented in this study are available on request from the corresponding author.

Conflicts of Interest: The authors declare no conflict of interest.

\section{References}

1. Singh, A.K.; Bedi, R.; Kaith, B.S. Mechanical properties of composite materials based on waste plastic? A review. Mater. Today-Proc. 2020, 26, 1293-1301. [CrossRef]

2. Torlakoglu, A.; Guclu, G. Alkyd-amino resins based on waste PET for coating applications. Waste Manag. 2009, 29, 350-354. [CrossRef] [PubMed]

3. Hiraga, K.; Taniguchi, I.; Yoshida, S.; Kimura, Y.; Oda, K. Biodegradation of waste PET: A sustainable solution for dealing with plastic pollution. EMBO Rep. 2019, 20, e49365. [CrossRef] [PubMed] 
4. Hopewell, J.; Dvorak, R.; Kosior, E. Plastics recycling: Challenges and opportunities. Philos. Trans. R. Soc. B-Biol. Sci. 2009, 364, 2115-2126. [CrossRef]

5. Mancini, S.D.; Schwartzman, J.A.S.; Nogueira, A.R.; Kagohara, D.A.; Zanin, M. Additional steps in mechanical recyling of PET J. Clean. Prod. 2010, 18, 92-100. [CrossRef]

6. Directive (EU) 2018/852 of the European Parliament and of the Council of 30 May 2018 Amending Directive 94/62/EC on Packaging and PackagingWaste. Available online: https://www.eea.europa.eu/policy-documents/directive-eu-2018-852-of (accessed on 2 February 2022).

7. Frounchi, M. Studies on degradation of PET in mechanical recycling. Macromol. Symp. 1999, 144, 465-469. [CrossRef]

8. Park, S.H.; Kim, S.H. Poly (ethylene terephthalate) recycling for high value added textiles. Fash. Text. 2014, 1, 1. [CrossRef]

9. Sinha, V.; Patel, M.R.; Patel, J.V. Pet Waste Management by Chemical Recycling: A Review. J. Polym. Environ. 2010, 18, 8-25. [CrossRef]

10. Koo, H.J.; Chang, G.S.; Kim, S.H.; Hahm, W.G.; Park, S.Y. Effects of recycling processes on physical, mechanical and degradation properties of PET yarns. Fibers Polym. 2013, 14, 2083-2087. [CrossRef]

11. Welle, F. Twenty years of PET bottle to bottle recycling-An overview. Resour. Conserv. Recycl. 2011, 55, 865-875. [CrossRef]

12. Nait-Ali, L.K.; Colin, X.; Bergeret, A. Kinetic analysis and modelling of PET macromolecular changes during its mechanical recycling by extrusion. Polym. Degrad. Stab. 2011, 96, 236-246. [CrossRef]

13. Lee, J.H.; Lim, K.S.; Hahm, W.G.; Kim, S.H. Properties of Recycled and Virgin Poly(ethylene terephthalate) Blend Fibers. J. Appl. Polym. Sci. 2013, 128, 1250-1256. [CrossRef]

14. Scelsi, L.; Hodzic, A.; Soutis, C.; Hayes, S.A.; Rajendran, S.; AlMa'Adeed, M.A.; Kahraman, R. A review on composite materials based on recycled thermoplastics and glass fibres. Plast. Rubber Compos. 2011, 40, 1-10. [CrossRef]

15. Giraldi, A.L.F.D.; Bartoli, J.; Velasco, J.; Mei, L. Glass fibre recycled poly(ethylene terephthalate) composites: Mechanical and thermal properties. Polym. Test. 2005, 24, 507-512. [CrossRef]

16. Kracalik, M.; Pospíšil, L.; Šlouf, M.; Mikešová, J.; Sikora, A.; Šimoník, J.; Fortelný, I. Effect of glass fibers on rheology, mechanical properties of recycled thermal and PET. Polym. Compos. 2008, 29, 915-921. [CrossRef]

17. Monti, M.; Scrivani, M.; Kociolek, I.; Larsen, Å.G.; Olafsen, K.; Lambertini, V. Enhanced Impact Strength of Recycled PET/Glass Fiber Composites. Polymers 2021, 13, 1471. [CrossRef]

18. Mondadori, N.M.L.; Nunes, R.; Canto, L.; Zattera, A.J. Composites of Recycled PET Reinforced with Short Glass Fiber J. Thermoplast. Compos. Mater. 2012, 25, 747-764. [CrossRef]

19. Albini, G.; Brunella, V.; Placenza, B.; Martorana, B.; Lambertini, V.G. Comparative study of mechanical characteristics of recycled PET fibres for automobile seat cover application. J. Ind. Text. 2019, 48, 992-1008. [CrossRef]

20. Atakan, R.; Sezer, S.; Karakas, H. Development of nonwoven automotive carpets made of recycled PET fibers with improved abrasion resistance. J. Ind. Text. 2020, 49, 835-857. [CrossRef]

21. Lin, C.C. Recycling technology of poly(ethylene terephthalate) materials. Macromol. Symp. 1998, 135, 129-135. [CrossRef]

22. Scheirs, J. Additives for the Modification of Poly(Ethylene Terephthalate) to Produce Engineering Grade Polymers; Wiley: Hoboken, NJ, USA, 2004

23. Wallach, M.L. Viscosity-molecular weight relation and unperturbed dimensions of polyethylene terephthalate. Die Makromol. Chem. 1967, 103, 19-26. [CrossRef]

24. Jabarin, S.A. Crystallization Kinetics of Polyethylene Terephthalate. 1. Isothermal Crystallization from the Melt. J. Appl. Polym. Sci. 1987, 34, 85-96. [CrossRef]

25. Tapia, J.J.B.; Hernandez-Valdez, M.; Cortez, J.C.; García, V.M.D.; Barrios, H.L. Improving the Rheological and Mechanical Properties of Recycled PET Modified by Macromolecular Chain Extenders Synthesized by Controlled Radical Polymerization. J. Polym. Environ. 2018, 26, 4221-4232. [CrossRef]

26. Elamri, A.; Abid, K.; Harzallah, O.; Lallam, A. Characterization of recycled/virgin PET polymers and their composites. Am. J. Nano Res. Appl. 2015, 3, 11.

27. Jagadeesh, D.; Kanny, K.; Prashantha, K. A review on research and development of green composites from plant protein-based polymers. Polym. Compos. 2017, 38, 1504-1518. [CrossRef]

28. Carrot, C.; Majesté, J.-C.; Olalla, B.; Fulchiron, R. On the use of the model proposed by Leonov for the explanation of a secondary plateau of the loss modulus in heterogeneous polymer-filler systems with agglomerates. Rheol. Acta 2010, 49, 513-527. [CrossRef]

29. Majeste, J.C.; Carrot, C.; Olalla, B.; Fulchiron, R. Internal Reorganization of Agglomerates as an Explanation of Energy Dissipation at Very Low Strain for Heterogeneous Polymer Systems. Macromol. Theory Simul. 2012, 21, 113-119. [CrossRef] 